\title{
Cancer in the world - a call for international collaboration
}

\author{
Mary K Gospodarowicz, MD, ${ }^{(1,2,3)}$ Eduardo Cazap, MD, ${ }^{(3,4)}$ Alex R Jadad, MD. ${ }^{(1,2)}$
}

C ancer is a major health problem in the world. ${ }^{1-3}$ Since the start of the $21^{\text {st }}$ century, cancer killed more people than died in World War II. This year, it is expected that there will be 12 million new cancer cases diagnosed and close to 8 million will die of cancer. This year it is expected that 1.4 million people will die from lung cancer with 866000 from stomach cancer, 653000 from liver cancer, 677000 from colon cancer and over half a million, 548000 deaths will be due to breast cancer. Today, a new breast cancer case in diagnosed in the world approximately every 25 seconds. It is estimated that by the year 2030, 12 million people will die each year if we do not act today and improve cancer control. At the same time our knowledge about cancer has never been greater. These statistics are a call for action. International collaboration across all sectors is needed to improve cancer control and reverse the trend.

Cancer arises from a change in one single cell and that change may be started by external agents and inherited genetic factors. Today, it is known that tobacco is the single most important external agent causing cancer. ${ }^{4}$ Almost $70 \%$ of all deaths in the world from cancer occur in the low- and middle-income countries. ${ }^{1}$ It is expected that $43 \%$ of cancer deaths be due to tobacco, poor diet, and infection. While over $40 \%$ of all cancers in the Western world are due to tobacco consumption and poor diet, in sub Saharan Africa the most common cancers are those related to infection. However, it is expected that increased penetration of tobacco consumption in the developing world, the deaths due to lung cancer and tobacco-related cancer will increase progressively.

Cancer is a diverse group if diseases, and cancer control is a complex issue. It is clear that a comprehensive approach is needed. Several years ago, the WHO has recommended that each country develop a national cancer control plan. ${ }^{5}$ The cancer control plan should address cancer registration, cancer prevention especially tobacco control, diet, alcohol consumption, physical activity, and chronic infection. It should also include a comprehensive set of public health and population based screening and early detection programs. High quality health care interventions must include multidisciplinary and multiprofessional team approach to care. It is important to deliver the right care to the right people at the right time by the right team. This mandates standardization of practice preferably through the application of evidence based practice guidelines adapted to the local situation. Education, training, and knowledge transfer are essential in providing the quality care; active research and innovation will drive the progress. Supportive and palliative care programs are essential.

(I) University of Toronto. Ontario, Canada.

(2) University Health Network. Toronto, Ontario, Canada.

(3) International Union Against Cancer. Geneva, Switzerland.

(4) Sociedad Latinoamericana y del Caribe de Oncología Médica. Buenos Aires, Argentina.

Received on: November 18,2008 - Accepted on: January 15, 2009

Address reprint requests to: Dr. Mary K. Gospodarowicz. Princess Margaret Hospital. 610 University Ave. Toronto, Ontario M5G2M9 Canada. E-mail: Mary.Gospodarowicz@rmp.uhn.on.ca 
There are numerous barriers to cancer control. Cancer control is closely linked to the economic situation. Lack of resources, whether material or human, lack of effective health care infrastructure are among the major economic barriers to cancer control. Additional barriers related to underfunding or poor organization of health care systems make cancer control difficult. Cancer registration is essential to plan adequate resource base and cancer control plans are needed to provide comprehensive care. In addition, in many parts of the world, the cultural barriers present problems. The diagnosis of cancer is still associated with shame and negative perception. It is widely believed in some countries that the diagnosis of cancer equals death and that serves as a huge barrier to the promotion of cancer prevention, screening and early detection, and effective treatment programs.

The disparities in cancer outcomes have been recently confirmed in a massive international CONCORD study of cancer survival in five continents. ${ }^{6}$ Global variations in cancer survival were enormous. Most of the wide global range in survival is likely due to the differences in access to diagnostic and treatment services.

Dr. John Seffrin, CEO of the American Cancer Society, talks about the "eight facts of cancer" ${ }^{7,8}$ They are:

1. That how cancer develops is no longer a mystery. We know how cancer develops in an individual and we have a lot of knowledge how it becomes an epidemic in the population.

2. That most human cancers could be prevented right now with tobacco control, with diet, exercise, and in control of infection.

3. That most cancer illness, suffering, and death could be avoided with the right cancer control plans and treatments being implemented.

4. That when faced with terminal cancer, state-ofthe-art care at the end of life results in death with dignity for most cancer patients and the suffering long associated with cancer no longer has to be true for a majority of cancer.

5. That the reduction in cancer mortality rates will have a beneficial effect on the economy.

6. That cancer can be brought under control as a public health system if we do the right things.

7. That if we fail to intervene, cancer will inevitably become the \#1 cause of death in the world.

8. That when compared to other health issues in the world, cancer is potentially the most preventable and the most curable of all life-threatening diseases.

These facts must be disseminated to improve the motivation of governments and health systems to im- prove cancer control. Cancer is probably the best studied and the most organized health problem addressed in the world today. There are numerous organizations that deal with cancers and there is a great deal of knowledge.

The International Union Against Cancer or Union Internationale contre le Cancer (UICC) is a 70-year-old non-governmental organization purely dedicated to the fight against cancer. ${ }^{9}$ Its mission is to build and lead the global cancer control community that is engaged in sharing and exchanging knowledge and competence, in transferring scientific funding to clinical, patient, and public settings, and in systematically reducing and eliminating disparities in the prevention, early detection, and treatment of cancer. In addition, UICC is committed to delivering the best possible care to people living with cancer in every part of the world. Currently, the UICC has four main strategic directions. The first one is cancer prevention and control. Because tobacco is such a huge problem in the world, tobacco control is a separate second strategic direction. The third direction of knowledge transfer engages other professional organizations and includes the fellowship programs and cancer staging classification. The fourth strategic direction, capacity building, and supports the development of nongovernmental voluntary and professional organization aimed to assist in the fight against cancer worldwide. The UICC's activities include the celebration of World Cancer Day, which is held on the $4^{\text {th }}$ of February each year. It is associated with promotion of the World Cancer Campaign. UICC holds World Cancer Congresses every two years. In the past, they have been held every four years but since 2006 in Washington, the congresses are now held every two years. The $21^{\text {st }}$ congress of the UICC will take place in Beijing, China from August 18-21, 2010. At the cancer congresses, the UICC adopts world cancer declaration, which outlines specific actions that the global cancer control community should take in the following 2 to 3 years. ${ }^{10}$

The first World Cancer Campaign was titled, "My Child Matters". ${ }^{9}$ Since then the campaigns have been dedicated to the issue of "Today's Children, Tomorrow's World". The reason for involvement of pediatric cancer and focus on children is that pediatric cancers are very highly curable diseases. In the high-income countries more than $90 \%$ of children can expect to be cured of cancer, while the cure rates for the same diseases in the low-income world can be as low as $10-20 \% .^{1}$ The cost of treating and curing pediatric cancer is low and there is no reason right now in the world why the high cure rates could not be available to all the children in the world.

At the Cancer Congress in Geneva in August 2008, the World Cancer Summit attracted the main cancer and political leaders in the world. Mary Robinson, the past 
president of Ireland and currently the President of 'Realizing Rights, The Ethical Globalization Initiative' talked about addressing inequities in cancer as a fundamental human right. She concluded that health is a fundamental human right and lowering the mortality from diseases should be given the same attention as any other human rights. The 2008 World Cancer Declaration sets out the targets to be realized by the year $2020 .{ }^{11}$ It is discussed in the paper by Dr. Eduardo Cazap, President-elect of the UICC. (ref)

UICC cannot accomplish these goals alone. ${ }^{12}$ Enormous resources are directed towards the fight against cancer worldwide. Most attention is devoted to research. Today, with the progress in molecular medicine, with mapping of the human genome, with the understanding that genetic changes drive cancer progression, resistance to treatment, and metastasis, there is great promise for improved diagnostic, predictive, and therapeutic interventions. Worldwide collaboration is needed to accelerate the progress of cancer research.

Breast cancer has been considered as a disease of developed world. However, data indicate growing breast cancer rates in middle and low resource countries. In Mexico, breast cancer deaths are eclipsing cervix cancer deaths. Breast cancer is also an increasing problem in India, Brazil and other countries. However, while developed and high resource countries struggle with cost of care and effective screening, the middle and low resource have to address the issues of cancer registration, access to care, lack of adequate resources for screening and treatment, and many myths and misconceptions about cancer. There is a need to share the effective interventions appropriate to the developing countries to accelerate the progress and reduce cost of progress.

Rapid adoption of innovation requires effective knowledge transfer system. Today, improved access to information facilitates research collaborations and reduces duplication of effort. Open source publishing offers even more timely access to information. ${ }^{13,14}$ Change is needed in granting mechanisms, academic promotion, and intellectual property issues to facilitate collaboration and information exchange. Information and communication technologies offer new possibilities for collaboration and new models of health care. ${ }^{15-19}$ E-health development is now on the agenda of most nations. ${ }^{20}$

The use of electronic health record, especially patient accessible records ${ }^{21,22}$, use of telehealth whether it relates to teleradiology, telepathology, e-tool kits, or asynchronous consultation all embrace the concept of collaboration and enhanced knowledge transfer. ${ }^{17,23,24}$ The use of Web 2.0 and social networks hold equal promise in knowledge transfer and patient engagement. ${ }^{18,25}$
Cancer control requires comprehensive interventions. Currently our cancer research efforts are skewed toward cancer treatment, mostly new drugs. Cancer research must include on one end, the investigation of improved prevention interventions, screening and early diagnosis. On the other end of the spectrum, we must continue to direct research in the issues related to quality life, supportive and palliative care and cancer survivorship. ${ }^{26}$ Today, whilst many patients are cured, the toll of treatment is greater than ever. Late effects of treatment have been recognized as an issue in childhood cancers, but they are increasingly becoming important in survivors of adult cancers. There are over 1 million cancer survivors in Canada today. Most adult cancer survivors include breast cancer, prostate cancer and colorectal cancer patients. They may experience late toxicities related to surgery, radiotherapy, hormone therapy and chemotherapy. The list of issues related to cancer is not limited to physical effects. Patients have psychosocial issues, problems with employment, insurance issues etc. The organized cancer system is not well suited to address these issues. Similar issues are seen in patients with chronic diseases such as diabetes, heart disease, arthritis, and others. Collaboration through the primary care providers is needed to optimize research and resource utilization in addressing survivorship issues.

The fight against cancer can be very successful. It is estimated that up to $30 \%$ of cancer deaths can be prevented. Cancer statistics in North America and in some European countries show significant decline in the rate of lung cancer pointing to the effectiveness of tobacco control policies regulations. In fact, the NCI US cancer trends progress report shows that the death rates for the four most common cancers (prostate, breast, lung, and colorectal), as well as for all cancers combined, continue to decline and the rate of cancer incidence has also declined. ${ }^{27-29}$

\section{References}

I. Cavalli F. Cancer in the developing world: can we avoid the disaster? Nat Clin Pract Oncol 2006;3:582-583.

2. Parkin DM, Bray F, Ferlay J, et al. Global cancer statistics 2002 . CA Cancer J Clin 2005;55:74-108.

3. Bray F, Moller B. Predicting the future burden of cancer. Nat Rev Cancer 2006;6:63-74.

4. Colditz GA, Sellers TA, Trapido E. Epidemiology - identifying the causes and preventability of cancer? Nat Rev Cancer 2006;6:75-83.

5.WHO. National Cancer Control Programmes: policies and managerial guidelines. Geneva, Switzerland: World Health Organization, 2002. 6. Coleman MP, Quaresma M, Berrino F, et al. Cancer survival in five continents: a worldwide population-based study (CONCORD). Lancet Oncol 2008;9:730-756. 
7. Seffrin JR. Cancer control as a human right. Lancet Oncol 2008;9:409-4II. 8.WHO Ua. Global Action Against Cancer. Geneva, Switzerland: World Health Organization, 2003.

9. International Union Against Cancer.Available at: www.uicc.org. Geneva, 2008

10. Cavalli F.The World Cancer Declaration: a roadmap for change. Lancet Oncol 9:8I0-I, 2008

II. UICC. World Cancer Declaration 2008. [accessed on: november 18,2008].Available in: http://www.uicc.org/index,php?option=com_content $\% 26$ task $=$ view $\% 26$ id $=\mid 4227 \% 26$ ltemid $=356$

12. Collingridge D. World Cancer Declaration: a need for partnership. Lancet Oncol 2008;9:915.

13. Eysenbach G. The open access advantage.J Med Internet Res 2006;8:e8 14. Eysenbach G. Citation advantage of open access articles. PLoS Biol 2006;4:el57.

15. Jadad AR, Enkin MW.The path towards eHealth: obstacles along the way.Yearb Med Inform 2006;84-87.

16. Jadad AR. A view from the Internet age: let's build a health system that meets the needs of the next generation. CMAJ 2004; I7I: I457- I458.

17. Rizo CA, Jadad AR, Meryn S. Use of the Internet for health information and communication. JAMA 2003;290:2257-2258.

18. Eysenbach G. Medicine 2.0: social networking, collaboration, participation, apomediation, and openness. J Med Internet Res 2008; 10:e22. 19. Eysenbach G. Poverty, human development, and the role of eHealth.J Med Internet Res 2007;9:e34.

20. Oh H, Rizo C, Enkin M, et al. What is eHealth (3): a systematic review of published definitions. J Med Internet Res 2005;7:el.
2I.Wiljer D, Urowitz S, Apatu E, et al. Patient accessible electronic health records: exploring recommendations for successful implementation strategies. J Med Internet Res 2008; 10:e34.

22. Urowitz S,Wiljer D, Apatu E, et al. Is Canada ready for patient accessible electronic health records? A national scan. BMC Med Inform Decis Mak 2008;8:33.

23. Quintana Y, Nambayan A, Ribeiro R, et al. Cure4Kids - building online learning and collaboration networks. AMIA Annu Symp Proc: 2003;978. 24. Heller LR, Gospodarowicz M, Jadad AR. eToolkits: improving pain management.J Pain Palliat Care Pharmacother 2007;21:67-70.

25. Bender JL, O'Grady L, Jadad AR. Supporting cancer patients through the continuum of care: a view from the age of social networks and computermediated communication. Curr Oncol 2008;15 Suppl 2:s107 es42-7.

26. Medicine lo. From cancer patient to cancer survivor: lost in translation. Washington DC: National Academies Press, 2005.

27. O'Leary M, Krailo M,Anderson JR, et al. Progress in childhood cancer: 50 years of research collaboration, a report from the Children's Oncology Group. Semin Oncol 2008;35:484-493.

28. Jemal A, Clegg LX,Ward E, et al. Annual report to the nation on the status of cancer, 1975-200I, with a special feature regarding survival. Cancer 2004;101:3-27.

29. Edwards BK, Brown ML,Wingo PA, et al. Annual report to the nation on the status of cancer, 1975-2002, featuring population-based trends in cancer treatment.] Natl Cancer Inst 2005;97: I 407- 1427. 